\title{
LÓPEZ OBRADOR O LA IZQUIERDA QUE NO ES
}

\author{
LÓPEZ OBRADOR OR THE ABSENT LEFT
}

\section{LÓPEZ OBRADOR OU LA GAUCHE QUI N'EN EST PAS UNE}

\author{
RAMÓn I. Centeno \\ Universidad de Sonora \\ ramon.centeno@unison.mx
}

Resumen: Por primera vez, la democracia mexicana tiene en el poder a un presidente que define a su gobierno como "posneoliberal". Al respecto, en este artículo explico que México está frente a la paradoja de un giro a la izquier$d a$ tan drástico como impotente. De lejos, el gobierno de Andrés Manuel López Obrador es el más poderoso que ha tenido la joven democracia mexicana; sin embargo, está muy lejos de desmontar al neoliberalismo. Aquí propongo que estamos frente a un progresismo fallido, por lo que concluyo que es un sinsentido conceptualizar como "de izquierda" a este gobierno.

Palabras clave: México; democracia; izquierda; neoliberalismo; populismo; progresismo; AMLO.

Abstract: For the first time, Mexican democracy has a president in power who defines his government as "post-neoliberal." In this article I explain how Mexico is facing the paradox of a turn to the left as drastic as it is impotent. By far, the government of Andrés Manuel López Obrador is the most powerful seen to date by Mexico's young democracy; however, it is nowhere near to dismantling neoliberalism. Here I propose that we facing a failed progressivism, and conclude that it makes no sense to conceive of this government as "left-wing."

Keywords: Mexico; democracy; left-wing; neoliberalism; populism; progressivism; AMLO.

\section{Traducción de Fionn Petch, CM Idiomas}

RÉsumé: Pour la première fois de son histoire, la démocratie mexicaine possède, à sa tête, un président qualifiant son gouvernement de «post-néolibéral». À ce sujet, mon article s'efforce d'expliquer en quoi le Mexique se retrouve 
face au paradoxe d'un virage à gauche aussi brusque qu'impuissant. Le gouvernement d'Andrés Manuel López Obrador est largement le plus puissant qu'ait connu la jeune démocratie mexicaine ; cependant, loin s'en faut qu'il déconstruise le néolibéralisme. Je défends ici l'idée que nous sommes face à un progressisme manqué et que, par conséquent, il ne rime à rien de qualifier ce gouvernement comme «de gauche».

Mots clés: Mexique; démocratie; gauche; néolibéralisme; populisme; progressisme; Andrés Manuel López Obrador.

Traducción de Ariel Elbaz, CM IDIOMAS

Fecha de recepción: enero de 2020

Fecha de aceptación: octubre de 2020 


\section{ILUSIÓN Y POLÍTICA}

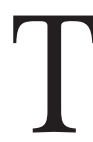

omar "mucha agua pura" y seguir "un camino de espiritualidad" fueron dos de las diez recomendaciones del presidente Andrés Manuel López Obrador (AMLO) "para salir del coronavirus". ${ }^{1}$ Al momento de lanzar su decálogo, México regresaba a "la nueva normalidad" que finalizaba las medidas de distanciamiento social en momentos en que el conteo oficial registraba más de 16000 muertes por la pandemia de Covid-19, la cual estaba aún lejos de ceder. Esta actitud política, un verdadero "sálvese quien pueda", hizo corto circuito con la imagen de un gobierno "de izquierda". Por ello, no es sorprendente que ganara terreno la tesis de que la pandemia marcó un antes y un después en el progresismo mexicano. La idea básica es que México iba viento en popa girando hacia la izquierda, pero la pandemia redujo seriamente las posibilidades y marchitó el impulso inicial del sexenio. ${ }^{2}$

Sin embargo, en este artículo refuto la noción prevaleciente de que la izquierda, algún tipo de izquierda, poco o muy moderada, pero izquierda al fin, gobierna en México. Para demostrarlo, aquí discuto la actuación del gobierno de AMLo antes de la pandemia, con lo que descarto la tesis del antes y después. La política que AMLo presentó para enfrentar los efectos de la pandemia ${ }^{3}$ ya era el centro de su actuación desde el inicio del sexenio. Por un lado, austeridad "republicana" en el marco de una disciplina fiscal sin impuestos a los más ricos; por el otro, algunos programas sociales (ninguno específico para la pandemia) y megaproyectos como el Tren Maya. El sexenio actual, que AMLo ha decretado como "el fin de la época neoliberal”, ha sido denunciado por la élite desplaza-

${ }^{1}$ Andrés Manuel López Obrador, "Decálogo para salir del coronavirus y enfrentar la nueva realidad”, México, Presidencia de la República, 2020.

${ }^{2}$ Por ejemplo, ver Viri Ríos, "En México solo hay dos partidos: conservador y conservador", The New York Times, 16 de junio de 2020.

${ }^{3}$ Andrés Manuel López Obrador, "La nueva política económica en los tiempos del coronavirus", México, Presidencia de la República, 2020. 
da como uno lleno de "amenazas al sistema democrático". ${ }^{4}$ Sin embargo, unos y otros se equivocan porque AMLO no está mudando ni de régimen económico ni político; más bien, les ha impreso un estilo específico. Para empezar, decía, ni siquiera es la izquierda la que llegó al poder.

Separarlo de la izquierda no debería ser controvertido, tomando en cuenta que AMLo ha afirmado que "el $90 \%$ de las llamadas que registran por violencia contra mujeres son falsas" y que juzga la legalización del aborto o el matrimonio entre personas del mismo sexo "comoalgo no tan importante". ${ }^{5}$ Sin embargo, ese tipo de posturas no han hecho mayor mella en el aura izquierdista que ha rodeado a este personaje; su supuesto compromiso redistributivo lo protege. Esto último, que considero un espejismo, me motivó a preparar este trabajo, en el cual recurro a la distinción izquierda-derecha desde una perspectiva marxista, es decir, como un filtro para clasificar posturas ante el capitalismo. En específico, uso esa distinción con respecto al neoliberalismo, entendido tanto como una reestructuración de las relaciones sociales en favor del capital como una correlación de fuerzas a la que dio origen. ¿Cómo incide tal o cual agente? ¿A la derecha (en favor del capital) o a la izquierda (en su contra)? El progresismo, en general, ha incidido ligeramente a la izquierda sin revertir el neoliberalismo.

El argumento central de este artículo es que estamos frente a un progresismo fallido en México, un desarrollo cuya comprensión pasa por analizar el contexto y la actuación de la tradición política de AMLo antes, durante y después de su ascenso a la Presidencia. La comparación con el resto de América Latina es un aspecto que atraviesa este trabajo, lo cual, sin ser el recurso clave, permitirá dimensionar el alcan-

${ }^{4}$ Ernestina Álvarez, "PAN pide a OEA llamar al gobierno a la estabilidad democrática en México", MVS Noticias, 29 de marzo de 2019.

5 "AMLO dice que el $90 \%$ de las llamadas sobre violencia contra las mujeres son falsas", Animal Político, 15 de mayo de 2020; "Para López Obrador, legalizar el aborto y el matrimonio gay no es algo 'tan importante' ", Animal Político, el 12 de junio de 2015. 
ce de varios procesos que aquí refiero. En especial, sostengo que el progresismo mexicano queda bastante deslucido comparado con el llamado "ciclo progresista" que definió a buena parte de la región en la década pasada.

El pasado político reciente favoreció el fracaso, pero este gobierno lo materializó con singular diligencia. El pasado reciente es el objeto del segundo y tercer apartado de este trabajo, donde examinaré, primero, la pronunciada deriva a la derecha del régimen mexicano y, después, la transmutación de la izquierda mexicana hacia coordenadas menos radicales. Esta situación -un régimen más a la derecha y una oposición menos a la izquierda-favoreció la paradoja de un giro a la izquierda tan drástico como impotente, a lo cual dedico los apartados cuarto y quinto. Por un lado, el presidencialismo mexicano alcanzó, en las elecciones de 2018-2019, su máximo poderío en lo que va del siglo (es decir, desde la democratización del régimen). Por el otro, la relación del gobierno de AMLO con el gran capital es tan conciliadora, que desfigura su impulso redistributivo y reduce a un mínimo (si no es que al absurdo) su proclamado "posneoliberalismo". A partir de las definiciones anteriores, en el sexto apartado propongo que el progresismo de AMLO no sólo es fallido, sino que ha virado a la derecha. Por último, concluyo que su fracaso permite, sin embargo, apreciar mejor el vacío de izquierda que hay en México y, por tanto, la necesidad de solventarlo.

\section{LA VÍA MEXICANA AL PROGRESISMO}

El neoliberalismo es la forma dominante del capitalismo contemporáneo, originado de una hipertrofia en su poderío que comenzó en los años setenta. En contra de las políticas de bienestar propagadas luego de la Segunda Guerra Mundial, como ha explicado David Harvey, la neoliberalización buscó y logró "la restauración del poder de clase" de la burguesía, 
desmontando victorias colectivas logradas en décadas previas. En su definición:

El neoliberalismo es, en primera instancia, una teoría de prácticas de economía política que propone que el bienestar humano puede impulsarse con mejores resultados mediante la liberación de las libertades y aptitudes empresariales individuales en un marco institucional caracterizado por derechos sólidos de propiedad privada, libre mercado y libre comercio. El papel del Estado es crear y conservar el marco institucional adecuado para tales prácticas. ${ }^{6}$

En el grueso de América Latina, el neoliberalismo tuvo sus años dorados en los noventa. Luego, a principios de siglo, vivió una crisis de hegemonía que abrió una oportunidad electoral a la oposición de izquierda; ése fue el fecundo terreno en el que nació el llamado "ciclo progresista". Parte de la legitimidad del giro neoliberal provenía de su calidad de protégé de la democratización. Las dictaduras militares habían sido derrotadas, dando pie a elecciones libres; el triunfo de la transición del autoritarismo a la democracia se respiraba fresco. Las paradojas del entrecruce de dicha transición con otra, del modelo de sustitución de importaciones al neoliberalismo, no fueron ignoradas por los transitólogos más notables. Guillermo O’Donnell, por ejemplo, se lamentaba:

En general, los gobiernos democráticos de la actualidad apoyan, implementan y conservan políticas con las cuales se ven favorecidos los sectores privilegiados. Esto incluye, para estos

6 David Harvey, A Brief History of Neoliberalism, Oxford, University Press, 2005, p. 2. Cita original: "Neoliberalism is in the first instance a theory of political economic practices that proposes that human wellbeing can best be advanced by liberating individual entrepreneurial freedoms and skills within an institutional framework characterized by strong private property rights, free markets and free trade. The role of the state is to create and preserve an institutional framework appropriate to such practices" (traducción de la editora). 
últimos, un mejor acceso a la formulación de políticas de lo que predominaba bajo los regímenes militares. ${ }^{7}$

En otras palabras, la añeja aversión de la burguesía latinoamericana a la democratización se atenuó cuando ésta demostró serle tan favorable; más aún, cuando la neoliberalización abrió un debilitamiento económico y político de las clases trabajadoras en el nuevo orden. En las palabras suaves pero precisas de Weyland: "el neoliberalismo ha fortalecido la sostenibilidad de la democracia en América Latina, pero ha limitado su calidad". ${ }^{8}$ Este balance de Weyland, fiel al mapa político latinoamericano de los noventa, había caducado al momento de su publicación. Con el cambio de siglo, Sudamérica experimentó el 'giro a la izquierda', cuyo clímax sería la existencia simultánea (y coaligada) de las presidencias de Hugo Chávez (1999-2013) en Venezuela, los Kirchner en Argentina (2003-2015), Evo Morales en Bolivia (2006-2019) y Lula en Brasil (2003-2011). La democracia seguiría en pie, pero su matrimonio con el neoliberalismo ya no podía darse por sentado. El giro a la izquierda sugería que en la región la ortodoxia neoliberal perdía su hegemonía: dejaba de convencer.

En México, por el contrario, primero vino el giro neoliberal y más adelante el democrático. El régimen autoritario, del Partido Revolucionario Institucional (PRI), que en su origen emergió como un árbitro entre las clases sociales, des-

7 Guillermo O'Donnell, "Poverty and Inequality in Latin America: Some Political Reflections", The Kellogg Institute Working Papers, núm. 225 (1996), p. 14. Cita original: "By and large, the present democratic governments are supporting, implementing, and maintaining policies under which the privileged sectors are faring very well. This includes, for these sectors, better access to policy-making than was the rule under military regimes" (traducción de la editora).

${ }^{8}$ Kurt Weyland, "Neoliberalism and democracy in Latin America: A mixed record", Latin American Politics and Society 46, núm. 1 (2004), p. 135. Cita original: "Neoliberalism has strengthened the sustainability of democracy in Latin America but limited its quality" (traducción de la editora). 
cansaba cada vez más en la burguesía. ${ }^{9}$ Este proceso, gradual, recibiría un fuerte impulso desde el exterior, en la década de los ochenta, en el contexto de la neoliberalización de las principales instituciones financieras mundiales. El Estado mexicano privatizó empresas estatales, propiedades comunales y recursos naturales. Para consolidar este orden, la agenda neoliberal moldeó un nuevo rol para el Estado, que pasó de dirigente y motor del capitalismo nacional a policía protector (y ocasional árbitro) del capital nacional y extranjero. La transformación neoliberal de México, por supuesto, no estaría exenta de rupturas en el régimen ni de resistencias de la oposición. El descontento, sin embargo, se expresó en las calles, sí, pero no llegó a la insurrección; también se expresó en las elecciones, sí, pero estas no fueron democráticas.

El régimen retuvo el poder y su arsenal político para enfrentar a la oposición fue muy distinto del que disponían los neoliberales sudamericanos. En México, el gobierno podía -además de reprimir- negociar las reformas neoliberales, las reformas democráticas o ambas. En Sudamérica, por otra parte, la democratización no estaba en la mira sino en el espejo retrovisor, con lo que la disputa se libró en el terreno de la economía política. En efecto, el gobierno mexicano respondió a la oposición, sí con represión, pero también con concesiones democráticas. ${ }^{10}$ Así, mientras las reglas del siste-

${ }^{9}$ Octavio Rodríguez Araujo, "México, proceso y afianzamiento de un nuevo régimen político”, Andamios 6, núm. 11 (2009), pp. 205-234.

${ }^{10}$ No es casualidad que la democratización recibiera su impulso definitivo luego de la insurrección zapatista de 1994. Planeada para coincidir con la entrada en vigor del Tratado de Libre Comercio de América del Norte (TlCAN), en enero de 1994, esta irrupción indígena en la selva de Chiapas cimbró la política mexicana y llevó al régimen a esforzarse en obtener para sí una legitimidad democrática. En consecuencia, el gobierno accedió a desvincular al Instituto Federal Electoral de la Secretaría de Gobernación y darle autonomía. Así, la organización de elecciones nacionales y el conteo de votos dejó de estar en manos del PRI. Un buen recuento de este proceso desde la perspectiva de quienes formularon las reformas jurídicas correspondientes está en Ma. del Carmen Alanís, "Carpizo y la reforma de 1994: una perspectiva neoinstitucional indivi- 
ma político llegaban a la mesa de negociación, las reformas neoliberales quedaban fuera de ésta.

No fue sino hasta el año 2000, una vez que la democracia había sido corroborada en la elección que sacó al PRI de la Presidencia, que el neoliberalismo dejó de estar amparado por un régimen autoritario y pasó a depender de las vicisitudes de una democracia emergente. Más adelante, en 2006, México estuvo a punto de vivir su giro a la izquierda. La expresión política liderada por AMLO -a la cual está dedicada la próxima sección- perdió la elección por un estrecho margen. ${ }^{11}$ En respuesta, el nuevo gobierno (2006-2012) del Partido Acción Nacional (PAN) lanzó la guerra contra el narcotráfico tan pronto tomó el poder. Iniciada como una táctica para ganar legitimidad en el corto plazo, la guerra al narco mutó en una estrategia de largo plazo del orden neoliberal. Produjo una atmósfera en que la violencia política o el despojo económico podían atribuirse a la locura de los narcos. El costo de este giro punitivo en el rumbo de la democracia mexicana ha llevado a más de un analista a diagnosticar un proceso de desdemocratización como antesala de una regresión autoritaria. ${ }^{12}$ Pero el otro costo, que acabo de insinuar, fue la profundización del orden neoliberal. El sexenio 2012-2018, liderado esta vez por un PRI resucitado, fue una

dualista”, en Miguel Carbonell, Héctor Fix y Diego Valadés (eds.), Estado constitucional, derechos humanos, justicia y vida universitaria. Estudios en homenaje a Jorge Carpizo, vol. 1, México, UnAM, 2015, pp. 33-52.

11 Aunque AmLo alegó fraude electoral, no se trató de una situación en la que el régimen informaba un resultado electoral que difería de la realidad en las urnas. Dicho esto, el presidente saliente, varios gobernadores, grandes capitalistas y sindicatos oficiales militaron abiertamente en contra del candidato de la izquierda de un modo que luego sería considerado ilegal por las autoridades electorales. Sin embargo, ¿en qué país capitalista no ocurre lo anterior? En Estados Unidos, considerado el ejemplo a seguir por nuestros politólogos, la situación es peor, pues ahí está legalizado el financiamiento directo de las corporaciones a los candidatos.

12 Ilán Bizberg, "México: una transición fallida”, Desacatos, núm. 48 (2015), pp. 122-139; Lorenzo Meyer, "Felipe Calderón o el infortunio de una transición”, Foro Internacional 55, núm. 1 (2015), pp. 16-44. 
continuación política del sexenio anterior aderezado de una nueva ola de reformas neoliberales, entre las que destaca la privatización de las reservas petroleras, luego de seis décadas de monopolio estatal. Así, el neoliberalismo llegaba a donde no pudo en el pasado.

En contraste con el Cono Sur, México ha personificado la continuidad neoliberal. Junto con Colombia y el Triángulo Norte de Centroamérica (Guatemala, El Salvador y Honduras), el malestar social causado en México por el neoliberalismo no enfrentó un giro a la izquierda, sino un 'giro punitivo' destinado a proteger -con más coerción que antes- el statu quo. La 'guerra contra el narcotráfico' en estos países -cofinanciada por el gobierno de Estados Unidos a través de la Iniciativa Mérida, el Plan Colombia y la Iniciativa Centroamericana de Seguridad Regional (CARSI, por sus siglas en inglés) - es la pieza política más notable de esta tendencia regional opacada por la atención captada por el progresismo sudamericano. De este modo, el "giro a la izquierda" de México en 2018, a diferencia de la ola sudamericana, ha tenido como punto de partida coordenadas políticas más a la derecha.

En su dimensión vernácula, el contexto de la irrupción lopezobradorista es el de la contrarrevolución neoliberal, no el de la Revolución mexicana. En comparación con el cardenismo -ese populismo primigenio del que AMLO procede-, la burguesía está cómoda en el sexenio actual y el proletariado está desmovilizado. Mientras Cárdenas tuvo que montar el México bronco de la agitación de organizaciones obreras y campesinas, AMLO es el cómodo portavoz del voto atomizado de 30 millones cuyo común denominador es él mismo.

En su dimensión regional, el contexto de la irrupción lopezobradorista es muy distinto del de la marea rosada sudamericana. Esta última pudo aprovechar el alza en los precios internacionales de las materias primas de la primera década del siglo, gracias al aumento de la demanda china. De ahí, del llamado neoextractivismo, provino una de sus principales fuentes de financiamiento del aumento del gasto social. En contraste, el progresismo mexicano llegó al poder en una 
constelación internacional signada por los efectos de la crisis financiera global de 2008. ${ }^{13}$ Uno de esos efectos fue la reducción del propio margen de maniobra de los gobiernos progresistas sudamericanos, que pronto se enfrentaron a un dilema que habían podido postergar: ¿afectar o no al capital para favorecer la justicia social?

En su titubeo frente a esta pregunta, está la clave del posterior volte-face de las bases sociales de partidos emblemáticos del progresismo, como el PT en Brasil y el PJ en Argentina. En cuanto al gobierno de AMLO, como explicaré más adelante, éste se ha enfrentado a dicho dilema desde el primer día, optando por evitar la confrontación con el capital. De esta forma, el progresismo mexicano nació muerto; estamos, así, ante un progresismo fallido.

\section{GÉNESIS DE UNA IZQUIERDA FALSA}

En los años setenta, una broma priista decía que "El que es joven y no es de izquierda está loco, pero el que después de los treinta sigue en la izquierda está todavía más loco”. En esos tiempos, el joven López Obrador ingresó a las filas del PRI. Ahora que tomó el poder, a sus 65 años, autodefinido como "de izquierda" y percibido como tal en el país, ¿cómo explicar la transfiguración de un político priista en un prócer de la izquierda? Esta paradoja es sólo una apariencia, pues en realidad AMLo no se pasó a la izquierda, sino que el país se movió a la derecha. Y en este desplazamiento tectónico, lo que fue la "izquierda" en la mayor parte del siglo xx quedó sustituido en el XXI por lo que era el "centro".

En palabras del historiador John Womack:

13 Por otro lado, la economía mexicana es menos dependiente de las materias primas que el resto de la región. Con el neoliberalismo, la industria manufacturera de México se reconfiguró como un enclave o satélite del capital estadounidense, lo cual significa que incluso si el progresismo hubiera gobernado en la década previa, no habría disfrutado del "efecto China” del modo en que sí lo hicieron sus pares sudamericanos. 
Mucha gente vio sus sueños izquierdistas realizados en el triunfo de López Obrador, pero lo que ahora llaman izquierda es una izquierda que, como tal, es muy pobre. No es la izquierda de Valentín Campa de los 50 y 60. Campa era comunista. Eso era la izquierda mexicana. Una izquierda marxista. ¿Qué es López Obrador en relación a eso? Para mí no hay izquierda fuera del marxismo. La izquierda no es izquierda a menos que sea marxista. El marxismo es crucial. El capitalismo es el punto central. O estás favor o estás en contra. ${ }^{14}$

La práctica extinción de la izquierda marxista en México es la expresión local de una derrota internacional. Con el desplome de la Unión Soviética se cerró un ciclo que empezó con la Revolución francesa y que durante dos siglos habilitó la existencia de una alternativa revolucionaria, socialista, al orden establecido. En consecuencia, sobrevino una época que aún está atravesada por una profunda crisis de la "imaginación utópica”, en palabras de Traverso. ${ }^{15}$ Aunque diminuta, la izquierda marxista mexicana, por decirlo así, existía. Con el fin del siglo xx casi desapareció y su espacio, vacante, fue ocupado por otras fuerzas.

López Obrador es un populista; proviene del viejo PRI y más tarde se sumó a esa parte que abandonó el partido cuando este se neoliberalizó. El PRI, cuya dominación en México se remonta a los años veinte del siglo xx, impulsó durante décadas un nacionalismo económico que sería el objeto de la crítica y reestructuración neoliberal. Operada por una nueva élite del partido, esta revisión ideológica condujo a su sector más cardenista a la ruptura. Este nuevo populismo, fundado por Cuauhtémoc (hijo de Lázaro) Cárdenas, compitió contra el partido del régimen en la elección de 1988. De esa escisión nació el PRD y, más recientemente, Morena. Pero López Obrador está

14 Dolia Estévez, "Con AMLo ganó la izquierda del PRI, y no la izquierda histórica, dice el historiador John Womack”, Sinembargo, 28 de julio de 2018.

15 Enzo Traverso, Melancolía de izquierda, Barcelona, Galaxia Gutenberg, 2019. 
a la derecha del nuevo populismo y muy a la derecha de Lázaro Cárdenas. Como sabemos, Cárdenas llegó a expropiar a capitalistas extranjeros; López Obrador, en contraste (y como veremos), está buscando el amor del gran capital.

La actual identificación de la izquierda con el populismo y no con el marxismo es un producto imprevisto de la neoliberalización mexicana. La corriente cardenista, al desprenderse del partido del régimen, absorbió al comunismo mexicano en el proceso, dando por resultado que, en las filas opositoras al neoliberalismo, la izquierda marxista cediera su lugar al priismo disidente. Sobre esto, Centeno ha insistido que no era inevitable la ingestión del comunismo por el populismo, sino que es un producto específico de la doctrina estalinista del frente popular que primó en la izquierda mexicana durante el siglo xx. ${ }^{16}$ A la derrota internacional del movimiento comunista con la restauración capitalista en el bloque socialista, la izquierda mexicana añadió su propia autodestrucción en el interior del priismo. No está de más recordar que la distancia política entre el marxismo y el populismo no es de grado, sino de orden; lo cual resulta evidente comparando sus respectivos horizontes estratégicos.

Como es sabido, en vísperas de la Primera Guerra Mundial el movimiento socialista se dividió entre reformistas y revolucionarios. Los primeros apostaban por un camino de reformas al capitalismo, en el marco de la democracia liberal, como vía al socialismo; reformas graduales, pero constantes. Y así, mediante un proceso de evolución natural, algún día se superaría el capitalismo. En su formulación clásica, Bernstein llegaría al extremo de afirmar: "El movimiento lo es todo; la meta final no es nada". A lo cual, Luxemburg contestaría que "el objetivo final del socialismo es el único factor decisivo que distingue al movimiento socialdemócrata de la democracia y

16 Ramón I. Centeno, “Zapata reactivado: una visión žižekiana del Centenario de la Constitución”, Mexican Studies/Estudios Mexicanos 34, núm. 1 (2018), pp. 36-62, https://doi.org/10.1525/msem.2018.34.1.36 
el radicalismo burgueses". ${ }^{17}$ De este modo, los revolucionarios sostenían, valga la redundancia, que no se podía superar al capitalismo sin una revolución, sin dejar a la burguesía en la lona, pues ella defendería sus privilegios y no dejaría de luchar para revertir las reformas logradas en su contra. Después de la Revolución rusa de 1917, los revolucionarios -a iniciativa de los bolcheviques- se redefinirían como "comunistas", dejando el apelativo de "socialdemócratas" a los reformistas.

De la mano de la Internacional Comunista, amparada en el prestigio de la Unión Soviética, los partidos comunistas en América Latina se convirtieron en sinónimo de la izquierda. Como rival de ésta, en cuanto a su vocación movilizadora de las clases populares, estaba el nacionalismo revolucionario o simplemente populismo. En comparación con la tradición socialista, el populismo latinoamericano converge con la socialdemocracia en su perfil reformista, pero diverge en sus objetivos. Los populismos "clásicos" de Cárdenas en México o Perón en Argentina no buscaban trascender, sino redefinir al capitalismo. A partir de una alianza con las clases populares, el Estado populista buscará imprimir a su capitalismo periférico una pauta más independiente de desarrollo, resultando en un ascenso de la industria nacional y una redistribución hacia abajo. El populismo estaría, sí, a la izquierda del fascismo y de las dictaduras militares, pero a la derecha de la vieja socialdemocracia.

Mientras el populismo es una tradición política añeja en América Latina, la socialdemocracia fue la novedad del reciente ciclo progresista. ${ }^{18}$ Irónicamente, la aparición de esta última tiene su origen en la conversión reformista de un sector de la izquierda comunista. Pero no el reformismo del debate clásico Bernstein-Luxemburg, sino uno que hace mucho abandonó el objetivo "de algo que solía llamarse 'socialismo"”

17 Rosa Luxemburg, Reforma o revolución, https://www.marxists.org/ espanol/luxem/1900/reform-revol.htm

${ }^{18}$ Jorge Lanzaro, Social democracias "tardías" Europa meridional y América Latina, Madrid, Centro de Estudios Políticos y Constitucionales, 2014, cap. 1. 
y cuya actitud en la era neoliberal oscila entre "la aceptación de las restricciones fiscales acompañado de políticas sociales remediales" y "el abrazo apasionado de las recetas neoliberales”, en palabras de Przeworski. ${ }^{19}$ Esta última actitud se acerca a los gobiernos de Bachelet, en Chile; la otra, estaría más cerca de Lula y Dilma en Brasil, y de Mujica y Vázquez en Uruguay.

A la izquierda de esta socialdemocracia "tardía”, y también en el contexto del último ciclo progresista, se colocaron los populismos de los Kirchner en Argentina, Correa en Ecuador, Morales en Bolivia y Chávez y Maduro en Venezuela. ${ }^{20}$ Por supuesto, estos casos no son iguales entre sí y, por ejemplo, para Katz sólo los dos últimos califican como "radicales" porque "aplicaron modelos de mayor redistribución y afrontaron severos conflictos con las clases dominantes". ${ }^{21}$ A diferencia del compromiso socialdemócrata con la democracia liberal, los populismos -de liderazgos más personalistas y con mayor vocación movilizadora- fluctúan entre lo

${ }^{19}$ Adam Przeworski, "How Many Ways Can Be Third?", en Social Democracy in Neoliberal Times. The Left and Economic Policy since 1980, Nueva York, Oxford University Press, 2001, pp. 312 y 325. Esa nueva socialdemocracia -hija de la atmósfera noventera signada por el giro neoliberal internacional, el colapso de la Unión Soviética y la configuración de un orden unipolar al mando de Estados Unidos-, postrada ante la nueva economía política, tiene como casos típicos afuera de nuestra región a la "tercera vía” del Partido Laborista británico (desde Tony Blair) y al Partido Socialista Obrero Español (desde Felipe González).

${ }^{20}$ La versión más famosa de la tesis de "las dos izquierdas" es, por supuesto, la de Jorge G. Castañeda, "Latin America's Left Turn", Foreign Affairs 85, núm. 3 (2006), pp. 28-43, https://doi.org/10.2307/20031965. Pronto se volvió un lugar común en la academia latinoamericanista reírse del simplismo (de derecha) de tal tesis. Sin embargo, el grueso de la academia crítica es castañedista, en su incapacidad para imaginar una izquierda distinta de la que llegó al poder en el giro a la izquierda regional. Se ha vuelto más fácil imaginar el regreso del "fascismo" que la reactivación, más o menos radical, de la tradición marxista u otras agendas anticapitalistas.

${ }^{21}$ Claudio Katz, "Desenlace del ciclo progresista", Estudios críticos del desarrollo 7 (2017), p. 90. 
que O’Donnell llamó "democracia delegativa” y la llana regresión autoritaria de Venezuela con Maduro y de Nicaragua con Ortega.

En la tradición populista habría dos subespecies: el viejo y el nuevo populismo; el primero más moderado que el segundo. ${ }^{22}$ En relación con estas coordenadas, el populismo de AmLo pertenece al tronco del viejo populismo, por su procedencia directa de la raíz priista. ${ }^{23}$ Sin embargo, y a diferencia de los demás populismos que han tomado el poder en la región en lo que va del siglo, el caso mexicano, como mostraré más adelante, es tan o más moderado que las expresiones socialdemócratas en relación con el capital.

Nuestro progresismo "tardío", decía, comparte con sus predecesores sudamericanos el mismo punto de partida: la doble transición a la democracia y al neoliberalismo. Pero, a diferencia de ellos, en México la reforma económica se instaló antes que la política. El neoliberalismo mexicano tuvo más tiempo para institucionalizarse y, como lo atestigua el caso chileno, esto reduce el margen de cambio del propio Estado. Por otro lado, durante la neoliberalización la izquierda mexicana sufrió una metamorfosis profunda en la que perdió radicalismo. El populismo cardenista se desprendió del régimen, pasó a la oposición y ocupó el espacio a la izquier-

22 Jorge Lanzaro, "La 'tercera ola' de las izquierdas latinoamericanas: entre el populismo y la social-democracia”, Encuentros Latinoamericanos 1, núm. 1 (2008), pp. 20-57.

${ }^{23}$ Puede afirmarse, incluso, que Morena es un populismo más puro, más parecido al viejo PRI de lo que fue el PRD. En este último eran perceptibles algunos rasgos socialdemócratas, producto de la izquierda socialista que se unió (y subordinó) al cardenismo que rompió con el PRI para formar el Frente Democrático Nacional, antecedente directo del PRD. De este origen procede la armazón ideológica que explica que los gobiernos de la Ciudad de México legalizaran, por ejemplo, el aborto (2007) y el matrimonio entre personas del mismo sexo (2010). No es casualidad, por cierto, que estas políticas no fueran impulsadas durante el periodo de gobierno de AMLO en la capital. Morena, en contraste con el PRD, se ha emancipado de cualquier reminiscencia socialista y se ha reconciliado de modo más pleno con su raíz priista, con su espíritu populista. 
da del espectro político (facilitado por la autodestrucción de la izquierda marxista). La tradición populista, que en 1968 era el verdugo de la "izquierda", se convirtió en su personificación. Esa tradición ganó la elección de 2018 y anunció el fin del neoliberalismo.

\section{TODO EL PODER AL PRESIDENTE}

En su pormenorizada genealogía de la noción de 'hegemonía' -desde la antigüedad griega hasta hoy, pasando por Antonio Gramsci-, Perry Anderson insiste que ésta es una relación que combina la coerción y el consentimiento. ${ }^{24}$ Una de las pocas definiciones que elogia es la de Ranajit Guha, según la cual la hegemonía es un tipo de dominación específico: uno donde la capacidad de convencimiento es mayor que la necesidad de imponerse por la fuerza. Si, a la inversa, la coerción predomina sobre el consentimiento, por supuesto sigue habiendo dominación, pero ya no puede hablarse de hegemonía. ${ }^{25}$ A partir de esta definición, se puede proponer que un desafío a la hegemonía neoliberal de un gobierno entrante "de izquierda" no podría llevarse a cabo con éxito sin una clara capacidad coercitiva.

AMLo está al frente de la Presidencia mexicana más poderosa bajo el régimen democrático, capaz de imponer reformas con una facilidad que no gozaron sus predecesores. Ningún candidato presidencial había tenido una victoria tan abultada en democracia. Con el $53 \%$ de los votos, AMLO superó a Vicente Fox, quien ganó la elección del año 2000 con

24 Perry Anderson, The H-Word. The Peripeteia of Hegemony, Londres, Verso, 2017.

25 "Guha developed an analytic model of such clarity and force that he could say, without emphasis but with reason, that he hoped it might resolve ambiguities in Gramsci's writings themselves" (Guha creó un modelo analítico de tal fuerza y claridad que podía decir, sin énfasis pero con razón, que esperaba resolver las ambigüedades de los escritos de Gramsci, trad. de la editora), Ibid., p. 153. 
el 43\%. Más allá del aura de legitimidad que le otorgó ese margen de aprobación, AMLo ganó mucho más que la Presidencia. Ni Fox, ni Calderón, ni Peña Nieto tuvieron tanto poder dentro del aparato estatal como el que obtuvo López Obrador, dueño y dios del partido dominante en las cámaras de diputados y de senadores, además de la mayoría de los congresos locales.

La capacidad coercitiva del gobierno de AMLo puede entreverse en el cuadro 1, donde se observa que desde 1997, con la emergencia de elecciones relativamente limpias, el partido del presidente no tenía la mayoría en la Cámara de Diputados. El subsecuente periodo de gobiernos divididos dio a la naciente democracia mexicana el sello de un presidencialismo moderado. Todo cambió con la última elección, de 2018, que fue una auténtica rebelión de los votantes contra los antiguos tres partidos dominantes (PRI, PAN y PRD), que se vieron reducidos a su mínima representación parlamentaria desde la transición.

\section{Cunadro 1}

Cámara de Diputados, 1994-2021. Porcentajes

\begin{tabular}{ccccccc}
\hline Legislatura & PRI & PAN & PRD & Morena & Otros & Total \\
\hline $1994-1997$ & 60 & 23.8 & 14.2 & & 2.0 & 500 \\
$1997-2000$ & 47.8 & 24.4 & 25.0 & & 2.8 & 500 \\
$2000-2003$ & 42.2 & 41.4 & 10.2 & & 6.2 & 500 \\
$2003-2006$ & 44.8 & 30.2 & 19.4 & & 5.6 & 500 \\
$2006-2009$ & 21.2 & 41.4 & 25.4 & & 13.0 & 500 \\
$2009-2012$ & 47.4 & 28.6 & 14.2 & & 9.8 & 500 \\
$2012-2015$ & 42.6 & 22.8 & 20.2 & & 14.4 & 500 \\
$2015-2018$ & 40.6 & 21.8 & 12.2 & 7.0 & 18.4 & 500 \\
$2018-2021$ & 9.4 & 15.6 & 2.2 & 51.8 & 21.0 & 500 \\
\hline
\end{tabular}

Fuente: Para el periodo 1994-2015, Rogelio Hernández Rodríguez, "El refugio del PRI durante la alternancia panista”, Foro Internacional 55, núm. 1 (2015), pp. 45-82. Para el resto, Instituto Nacional Electoral. 
Con la irrupción de Morena, por lo tanto, el presidencialismo mexicano ha recobrado su tradicional esplendor, si bien dentro de los límites impuestos por el fin del autoritarismo. La victoria de AMLO se suma, por lo tanto, a los cuatro giros a la izquierda que en Sudamérica lograron mayoría legislativa: Venezuela en 2000 (55.8\%), Argentina en 2001 (50.1\%), Uruguay en 2004 (52.5\%) y Bolivia en 2005 (55.4\%). Sin embargo, el dominio parlamentario de Morena es aún mayor de lo que parece, si le agregamos la representación de sus aliados, el Partido Encuentro Social (5.8\%) y el Partido del Trabajo (5.6\%). De este modo, la coalición que llevó a AMLo al poder tiene casi dos tercios de los diputados.

La situación en la Cámara de Senadores no es muy distinta de lo ocurrido en la cámara baja (véase cuadro 2). La antigua tríada dominante (PRI, PAN y PRD) cayó a su mínima expresión histórica y su representación combinada apenas junta una tercera parte de los senadores. En cambio, la coalición gobernante tiene más de la mitad, si sumamos a Morena la representación de sus aliados, el PES (3.9\%) y el PT $(4.7 \%)$.

Cuadro 2

Cámara de Senadores, 1994-2024. Porcentajes

\begin{tabular}{rrrrrrr}
\hline Legislatura & PRI & PAN & PRD & MORENA & Otros & Total \\
\hline $1994-1997$ & 66.7 & 25.0 & 8.3 & & & 96 \\
$1997-2000$ & 59.4 & 25.8 & 13.3 & & 1.6 & 128 \\
$2000-2006$ & 46.9 & 35.9 & 12.5 & & 4.7 & 128 \\
$2006-2012$ & 25.8 & 40.6 & 22.7 & & 10.9 & 128 \\
$2012-2018$ & 42.2 & 29.7 & 17.2 & & 10.9 & 128 \\
$2018-2024$ & 10.9 & 18.8 & 3.9 & 46.1 & 20.3 & 128 \\
\hline
\end{tabular}

Fuente: Instituto Nacional Electoral.

¿Pero acaso Amlo tiene a Morena bajo su control? Porque bien podría ser que este partido, nuevo como además lo es (fundado en 2014), fuera todavía una masa relativamente amorfa y 
heterogénea cuyo control se escurre de entre los dedos del presidente. La realidad, sin embargo, es justo la contraria. La juventud de Morena ha facilitado y acentuado la dependencia que el nuevo partido tiene de AMLO, su fundador y líder máximo e indiscutido. Cuando éste, por ejemplo, obtuvo el cargo de presidente de Morena fue por aclamación, en votación unánime a mano alzada, y no en una votación secreta. Diversos analistas han documentado el liderazgo carismático de AMLO en Morena, un rasgo transplantado desde el PRD y que pronto adquirió centralidad en su proceso de formación, fundación y consolidación. ${ }^{26}$ En pocas palabras, AMLO es el caudillo del partido que hoy domina el sistema político mexicano, en el cual él es el presidente.

En el presente, ésta es la única democracia del continente en esta situación, que guarda similitud con lo que fue Bolivia con Morales o Venezuela con Chávez, si bien en el caso mexicano es difícil prever la reelección de AMLO, dada la fuerte tradición en contra de esta práctica desde la Revolución de 1910. La bicéfala condición de AMLo como jefe del Estado y del partido dominante repite (y, no olvidemos, proviene de) las viejas tradiciones del PRI, con la importante salvedad de que la transición democrática obligará al sucesor de AMLO a ganarse la presidencia en una elección competitiva y, por lo tanto, sin que baste el "dedazo".

Los rasgos propios del carisma pronto se hicieron presentes en el nuevo gobierno. Luego de que AmLO asumiera el poder el $1^{\circ}$ de diciembre de 2018, Porfirio Muñoz Ledo,

${ }^{26}$ Por ej., Alberto Espejel, "Orígenes organizativos y derroteros estatutarios del Movimiento de Regeneración Nacional y el Partido de la Revolución Democrática. Entre carisma y grupos políticos”, Estudios Políticos 35 (2015), pp. 103-128, https://doi.org/10.1016/J.ESPOL.2015.03.002; Ricardo Espinoza Toledo y Juan Pablo Navarrete Vela, "MORENA en la reconfiguración del sistema de partidos en México”, Estudios Políticos 37 (2016), pp. 81-109, https://doi.org/10.1016/J.ESPOL.2016.02.004; Rosendo Bolívar Meza, "Movimiento de Regeneración Nacional: democracia interna y tendencias oligárquicas”, Foro Internacional 57, núm. 2 (2017), pp. 460-489, https://doi.org/10.24201/fi.v57i2.2385 
presidente de la Cámara de Diputados (y de las filas de Morena) declaró en Twitter: "Desde la más intensa cercanía confirmé ayer que Andrés Manuel ha tenido una transfiguración: se mostró con una convicción profunda, más allá del poder y la gloria. Se reveló como un personaje místico, un cruzado, un iluminado". Más allá del carácter anecdótico de esta declaración, el punto es que los subordinados de AMLo lo tratan justo como el personaje que se le "reveló" a Muñoz Ledo. Así, las conferencias de prensa que AMLO ofrece todos los días (las mañaneras) no son simples charlas (a modo) con los periodistas. Dichas conferencias (en realidad, monólogos) son objeto del análisis cotidiano de las diferentes secretarías para determinar las políticas a seguir, en detrimento del procedimiento burocrático habitual.

Con todo, Morena no tiene el poder en los gobiernos estatales que disfrutó el PRI incluso durante su declive en la transición democrática, como puede verse en el cuadro 3. Sin embargo, apenas existe como partido desde 2014 y el calendario electoral de cada estado no coincide necesariamente con el de la renovación de la administración federal. Además, en 2019 se renovaron dos gubernaturas, Puebla y Baja California, que gobernaba el PAN y que en esta ocasión ganó Morena.

Cuadro 3

Gubernaturas por partido político, 1988-2018

\begin{tabular}{ccccccc}
\hline Partido & 1988 & 1994 & 2000 & 2006 & 2012 & 2018 \\
\hline PRI & 30 & 28 & 20 & 17 & 21 & 12 \\
PAN & 1 & 3 & 9 & 9 & 6 & 11 \\
PRD & 0 & 0 & 3 & 6 & 3 & 2 \\
Morena & & & & & & 4 \\
Otros & 0 & 0 & 0 & 0 & 2 & 3 \\
\hline
\end{tabular}

Fuente: Hernández Rodríguez, op. cit., para el periodo 1988-2006. Para el resto, Institutos Electorales Estatales. 
La relativamente reducida presencia de Morena en las gubernaturas podría llevar a inferir en forma precipitada que el alcance de la Presidencia es, a final de cuentas, débil. Sin embargo, ese partido es el más representado en 21 de los 30 congresos locales que se renovaron en 2018 y 2019. ${ }^{27}$ Con esto, el partido del presidente puede obstruir a los gobernadores de oposición, los cuales tienen que negociar con un Palacio Nacional descollante.

Con AMLO, el presidencialismo mexicano se aproxima a la famosa "democracia delegativa" de O'Donnell, quien circunscribía tal fenómeno al Tercer Mundo, aunque hoy lo mismo podría decirse de Estados Unidos con Trump en el poder (si no es que desde antes). La hipertrofia del poder presidencial en regímenes con elecciones libres y competitivas no es en sí misma un síntoma de una dictadura en gestación; más bien es testimonio de los propios límites del presidencialismo como forma de "democracia". ${ }^{28}$

México fue un sistema presidencialista antes de la democratización y lo sigue siendo después de ella. Pero López Obrador, a diferencia de los demás presidentes de la era democrática, tiene al Congreso en la bolsa. En efecto, Ló-

${ }^{27}$ Por sí solo, Morena obtuvo la mayoría absoluta en nueve congresos locales, pero si consideramos a la coalición de Morena, PT y PEs, este número se eleva a 18.

${ }^{28}$ El planteamiento hoy clásico de los límites del presidencialismo es, por supuesto, el de Linz, quien toma partido por el parlamentarismo. Véase Juan J. Linz, "The perils of presidentialism”, Journal of democracy 1, núm. 1 (1990), pp. 51-69, https://doi.org/10.1353/jod.1990.0011. Una conclusión análoga, desde otra cartografía de las clases sociales (esto es, sin burguesía), ha sido adoptada por algunos marxistas. Perry Anderson, por ejemplo, opina que un serio defecto de las independencias latinoamericanas fue "la servil imitación de la constitución de los Estados Unidos del siglo xviII", y agrega: "Una democracia profunda exige exactamente lo opuesto a este poder plebiscitario. Precisa de un sistema parlamentario fuerte, basado en partidos disciplinados, con financiamiento público equitativo y sin demagogias cesaristas". Véase Perry Anderson citado en Emir Sader y Pablo Gentili (eds.), La trama del neoliberalismo (2 $2^{\mathrm{a}}$ ed.), Buenos Aires, Clacso, 2003, p. 86. 
pez Obrador tiene en sus manos un enorme control del Estado, más que suficiente para girar cómodamente el volante hacia la izquierda.

\section{TODO EL PERDÓN AL GAPITAL}

En su cuarto mes de gobierno, AMLO decretó "el fin de la época neoliberal" desde Palacio Nacional: "Quedan abolidos el modelo neoliberal y su política de pillaje antipopular y entreguista [...]. Ahora tenemos la responsabilidad de construir una nueva política posneoliberal". ${ }^{29}$ Un mes después, su visión "posneoliberal" quedaría plasmada en el Plan Nacional de Desarrollo. A pesar de su grandilocuencia (o, más bien, gracias a ella), el progresismo mexicano contradice lo que afirma con lo que lleva a la práctica.

AMLO es un admirador del "desarrollo estabilizador" (1952-1970) en virtud de la fuerte presencia y actividad del Estado en la economía. En este sentido, se adscribe al neodesarrollismo inaugurado por el progresismo sudamericano. La nostalgia de AMLO, sin embargo, viene acompañada de resignación. Ya como presidente, ha observado que "sería imposible y hasta disparatado intentar un retorno a las estrategias del desarrollo estabilizador". ${ }^{30}$ En cuanto a la neoliberalización, AMLO ha mantenido su oposición. No sorprende, por lo tanto, que un capítulo del último libro firmado por él se titulara "Privatizar, sinónimo de robar". En ese panfleto, AMLo explica que en México el "neoliberalismo" fue un vehículo "para llevar a cabo los robos más grandes que se hayan registrado en la historia del país”. Como ejemplo de ello, nos recuerda que entre 1988 y 1993 "se enajenaron 251 empresas del sector público; es decir, se privatizaron compañías

${ }^{29}$ Alonso Urrutia y Dora Villanueva, "López Obrador decreta el 'fin de la época neoliberal'”, La Jornada, 18 de marzo de 2019.

30 Presidencia de la República, Plan Nacional de Desarrollo 2019-2024, México, 2019. 
como Telmex, Mexicana de Aviación, Televisión Azteca...”.31 Luego de pintar este cuadro desolador, que incluyó la privatización de "tierras ejidales, las autopistas, los puertos y los aeropuertos", uno esperaría alguna ruta para revertir el daño. Pero muy lejos de ello, AMLo aprovechó el mismo libro para lanzar una "amnistía anticipada" a la elite neoliberal, con la que disfrazó de graciosa misericordia lo que en verdad es una rendición anticipada; un armisticio antes de la batalla:

Les decimos a los integrantes del grupo en el poder que, a pesar del gran daño que le han causado al pueblo y a la nación, no les guardamos ningún rencor y les aseguramos que, ante su posible derrota, en 2018, no habrá represalias o persecución para nadie. ${ }^{32}$

Ya como presidente, AMLO refrendó su sumisión (su "amnistía”) a las relaciones de propiedad configuradas durante la neoliberalización, pintándolo de cuerpo entero, al ganar la elección de 2018 agitando contra el neoliberalismo para en seguida absolverlo. ${ }^{33}$ En el Plan Nacional de Desarrollo aclaró que "el gobierno federal respetará los contratos suscritos por administraciones anteriores, salvo que se comprobara que fueron obtenidos mediante prácticas corruptas, en cuyo caso se denunciarán ante las instancias correspondientes". ${ }^{34}$ La contradicción de enfrentar la corrupción a través del marco jurídico

${ }^{31}$ Andrés Manuel López Obrador, 2018 La Salida, México, Planeta, 2017, pp. 9-10.

${ }^{32}$ Ibid., p. 72.

${ }^{33}$ En su discurso de triunfo la noche de la elección, AmLo sintetizó su agenda de gobierno. Lo primero que dijo fue que "habrá libertad empresarial", antes de mencionar la "libertad de expresión, de asociación y de creencias". También adelantó que "se respetará la autonomía del Banco de México; el nuevo gobierno mantendrá disciplina financiera y fiscal; se reconocerán los compromisos contraídos con empresas y bancos nacionales y extranjeros". Además, aseguró que "no habrá confiscación o expropiación de bienes".

${ }_{34}$ Presidencia de la República, Plan Nacional de Desarrollo 2019-2024, op. cit., p. 49. 
que legalizó "los robos más grandes" (y sus contratos) es una ratificación del indulto de AMLO a estos últimos.

Su gobierno ha hecho las paces con el capital, pero no con el Estado, al que desea reorientar hacia la justicia social. Pero, ¿cómo lograrlo sin molestar al capital? El progresismo mexicano, en efecto, tiene una aspiración redistributiva y en esto se asemeja a la ola sudamericana. Sin embargo, y a diferencia de aquella, lo que distingue al caso mexicano es su timidez para (por lo menos) implementar una reforma fiscal progresiva que permitiría financiar la política social. Luego de autoimponerse la postergación de una reforma de este tipo para "la segunda mitad de esta administración", 35 pero sin anticipar detalles, AMLO pronto elevó la austeridad al alfa y omega de su gobierno:

El Paquete Económico 2019 se sustenta en dos pilares. El primero de ellos es un compromiso con la disciplina fiscal y financiera, de manera que se garantice estabilidad macroeconómica y el fortalecimiento de las finanzas públicas. El segundo pilar descansa en la observación escrupulosa de los principios de austeridad... ${ }^{36}$

El primer pilar es testimonio del compromiso del gobierno de AMLO con la continuidad neoliberal. El segundo pilar, por otra parte, constituye una verdadera innovación: es la primera vez que un gobierno "posneoliberal" adopta la austeridad como uno de sus "pilares". Por el contrario, en Europa, en el contexto de adelgazamiento del Estado de bienestar, la ecuación neoliberalismo=austeridad es parte del sentido común. Por su parte, AMLo justificó la austeridad presentándola como la solución contra la corrupción. ${ }^{37}$ Ya en el poder,

${ }^{35}$ Secretaría de Hacienda y Crédito Público, SHCP, "Criterios Generales de Política Económica para la Iniciativa de Ley de Ingresos y el Proyecto de Presupuesto de Egresos de la Federación Correspondientes al Ejercicio Fiscal 2019”, México, 2018, pp. 3, 74.

36 Ibid., p. 85.

37 Para Amlo, "En México, la causa principal de la desigualdad es la corrupción”. Además, en una curiosa réplica al fantasma del marxismo, 
formularía la lucha anticorrupción como un ataque a los privilegios, los "gastos suntuarios", de la alta burocracia. ${ }^{38}$ Lo anterior en realidad encerraba un recorte a todos los niveles del Estado en favor de los programas sociales del obradorismo; es decir, la austeridad (como reasignación presupuestaria) en sustitución de impuestos a los más ricos:

[L] os compromisos de no incrementar los impuestos, de garantizar la estabilidad macroeconómica y de mantener las finanzas públicas sanas hace que sea necesario realizar una reasignación importante de recursos en el presupuesto. [...] Con la eliminación de programas y gastos con poco impacto social y productivo se contribuirá a financiar gasto en infraestructura y programas sociales prioritarios, lo cual incrementará la eficiencia en el presupuesto sin comprometer la disciplina fiscal. ${ }^{39}$

En contraste, la tradición socialdemócrata tiene una inclinación por reformas tributarias progresivas que amplíen la base fiscal como precondición de la política redistributiva (o en términos presupuestarios, del gasto social). Por su parte, y a diferencia, por ejemplo, de Chile con Bachelet o Uruguay con el Frente Amplio, con AmLo en México se ha inventado la austeridad progresista: una disciplina fiscal que aporta un aroma de izquierda a la economía política neoliberal. Una

explicó que "la monstruosa desigualdad que tenemos no se debe a la explotación del empresario al obrero". En otra oportunidad, amplió la misma idea: "Los académicos más clásicos, más teóricos, se quedaron con la idea de que la desigualdad se produce por la explotación que se hace de los trabajadores [...]. Pero en México no aplica esa teoría del todo". Para cada declaración consultar, respectivamente, "Entrevista en casa de AMLO", México, TV Azteca, 2018; “Amlo en Los Reyes Acaquilpan”, México, American News, 2018.

38 Presidencia de la República, "No se gastará más dinero del que ingrese a la hacienda pública. Los recursos destinados a financiar los programas sociales provendrán de lo que se ahorre con el combate a la corrupción y la eliminación de gastos suntuarios, desperdicio de recursos y robo de combustibles", Plan Nacional de Desarrollo 2019-2024, pp. 48-49.

${ }^{39}$ SHCP, op. cit., p. 3. 
estrategia rimbombante pero fallida. De hecho, como puede apreciarse en la gráfica 1, la inversión en programas sociales de los dos primeros años del gobierno de AMLO fue prácticamente la misma y, aunque fue superior en $5.1 \%$ al gasto de 2018, el último año de Peña Nieto, estuvo por debajo de la inversión de los primeros cuatro años de este último. En términos presupuestales, los programas de AMLO están lejos de ser "la reforma social más importante de los últimos tiempos”. ${ }^{40}$

\section{GRÁFICA 1}

Gasto en programas sociales, subsidios y relacionados

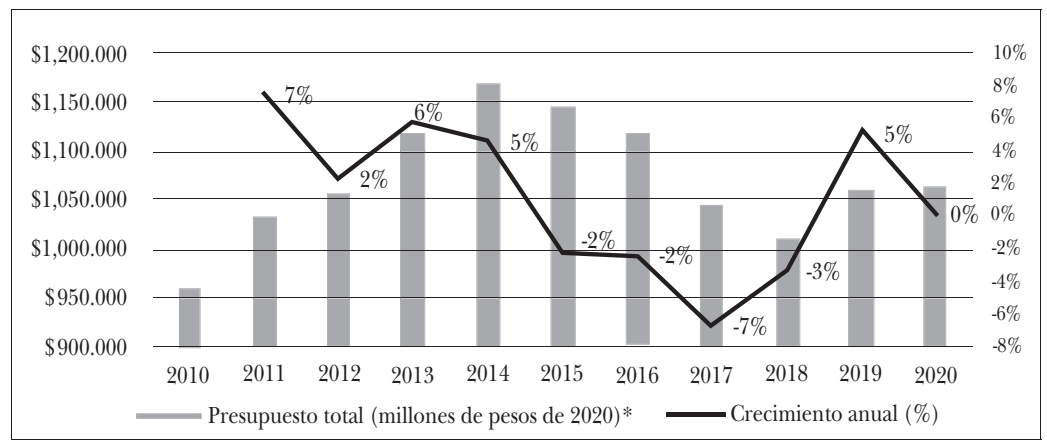

Fuente: elaboración propia a partir del Inventario Coneval de Programas y Acciones Federales de Desarrollo Social.

* Sobre datos disponibles al momento de consulta: para los años 20102018, tomé el presupuesto ejercido; para 2019, el presupuesto modificado; y, para 2020, el presupuesto original.

Además, como ha explicado el analista Máximo Jaramillo, los programas sociales de AMLo están lejos de representar "un cambio paradigmático para la política social” y su principal novedad es la opacidad (ausencia de reglas de operación

${ }^{40}$ Andrés Manuel López Obrador, "Discurso del presidente Andrés Manuel López Obrador en su informe al pueblo de México", Presidencia de la República, 5 de abril de 2020. 
y ocultamiento del padrón de beneficiarios, por ejemplo) ${ }^{41}$ El cuadro no es mejor en cuanto a cobertura, pues los 22 millones de beneficiarios reportados por AMLO en sus programas sociales representan una reducción frente a los 26.8 millones que tuvo Prospera en 2017, lo que puso en ridículo promesas temerarias como la siguiente, emitida en plena pandemia de Covid-19: "El primero de diciembre de este año [2020] podré decir que todos los pobres de México ya cuentan con protección y amparo del gobierno que represento". ${ }^{42}$

Desde el inicio, AMLO apretó el cinturón todavía más de lo planeado a ciertas áreas del Estado. A diferencia de Robin Hood, que les quitaba a los ricos para darle a los pobres, AMLo le quita a unos pobres para darle a otros, evocando así a un Robin Hood horizontal. Al lado de medidas rimbombantes, como un ajuste del gasto de la Presidencia por $-66.5 \%$, sobrevino un ajuste al IMss y al Issste por $-6.8 \% .{ }^{43}$ Por supuesto, cada porcentaje se refiere a un monto muy distinto: 519 mdp de la Presidencia contra 36174 mdp del IMss y el IsssTE. Este ajuste colocó a las instituciones de seguridad social en verdaderas dificultades de operación. ${ }^{44}$ El primer director del IMss del sexenio renunciaría debido a los recortes en ese instituto y, poco después, renunciaría el propio titular de la Secretaría de Hacienda y Crédito Público (shcP), Carlos Urzúa, en desacuerdo con los recortes adicionales que AMLo ordenó sobre el plan de austeridad original (diseñado por Urzúa). La ultra-austeridad adoptada conduciría a la iró-

41 Máximo Jaramillo, “¿Una nueva política social?: cambios y continuidades en los programas sociales de la 4T”, Análisis Plural, (julio-diciembre de 2019), p. 153.

42 López Obrador, "Discurso del presidente...", op. cit. Andrés Manuel López Obrador en su informe al pueblo de México”.

43 Secretaríad de Hacienda y Crédito Público, SHCP, "Informe sobre la situación económica, las finanzas públicas y la deuda pública. Segundo trimestre 2019”, México, 2019.

44 David Agren, “AMLO's Mexico leads to drastic cuts to health system”, The Lancet 393, núm. 10188 (el 8 de junio de 2019, pp. 2289-2290, https://doi.org/10.1016/S0140-6736(19)31331-5 
nica situación de ver a una calificadora financiera haciendo una crítica keynesiana al gobierno por impactar negativamente en el crecimiento del producto interno bruto, indicando que "resulta vital evitar un ciclo vicioso donde los recortes al gasto debiliten aún más la economía”. ${ }^{45}$

De conjunto, la única política del gobierno de AMLo capaz de incomodar directamente al capital ha sido el aumento al salario mínimo, el más importante en el periodo neoliberal. Dicho indicador se deterioró tanto, que el aumento de los primeros dos años del sexenio apenas lo acerca a su nivel de 1989, como se observa en la gráfica 2. El objetivo para el salario mínimo del actual gobierno es "alcanzar, al final de la actual administración, el nivel de 1976”. ${ }^{46}$ No cabe duda que, de lograrse, esta meta tiene el potencial de desestabilizar las relaciones capital-trabajo. Hasta ahora, cuando esas fricciones han escalado, el gobierno de AMLo ha contenido a los trabajadores en favor del capital. ${ }^{47}$

En la frontera con Estados Unidos el aumento fue aún mayor y en 2020 rondó los $\$ 185.56$ diarios, monto cercano al nivel de 1983. El gobierno federal explicó que el aumento diferenciado buscaba contener la emigración en "la última cortina de desarrollo" (la frontera norte). Lo cierto es que el aumento fronterizo, en particular, y el aumento nacional, en general, son producto de una imposición externa, originada

45 "Preocupa política de gasto; austeridad afectó PIB: HR Ratings", El Economista, 11 de agosto de 2019.

46 Comisión Nacional de Salarios Mínimos, Conasami, "Boletín No. 002/2019”, México, Secretaría del Trabajo y Previsión Social, 2019.

${ }^{47}$ En enero de 2019, las empresas maquiladoras de la franja fronteriza suprimieron prestaciones a sus trabajadores con el fin de neutralizar los efectos del aumento salarial. La expresión más amplia de descontento obrero se dio en Matamoros, ciudad que vio la primera huelga general del siglo en México. Cuando la huelga alcanzó su punto climático, el gobierno de AMLO fue orillado a tomar partido: ¿estaba con los huelguistas o con sus empleadores? La respuesta vino de boca de Alfredo Domínguez, subsecretario del Trabajo: "Consideramos que el estallamiento de huelga no beneficia a ninguna de las dos partes". "Huelga en Matamoros no beneficia a nadie: stPs", Forbes, 25 de enero de 2019. 
en las negociaciones entre Estados Unidos, Canadá y México para el T-MEC, el acuerdo que sustituyó al Tratado de Libre Comercio de América del Norte. El nuevo acuerdo exige que $40 \%$ del valor creado en la industria automotriz provenga de trabajadores que ganen al menos 16 dólares la hora, lo que hoy equivale a nuestro salario mínimo fronterizo, ¡de 2 días! ${ }^{48}$

GráficA 2

Salario mínimo real en México (1976-2020)

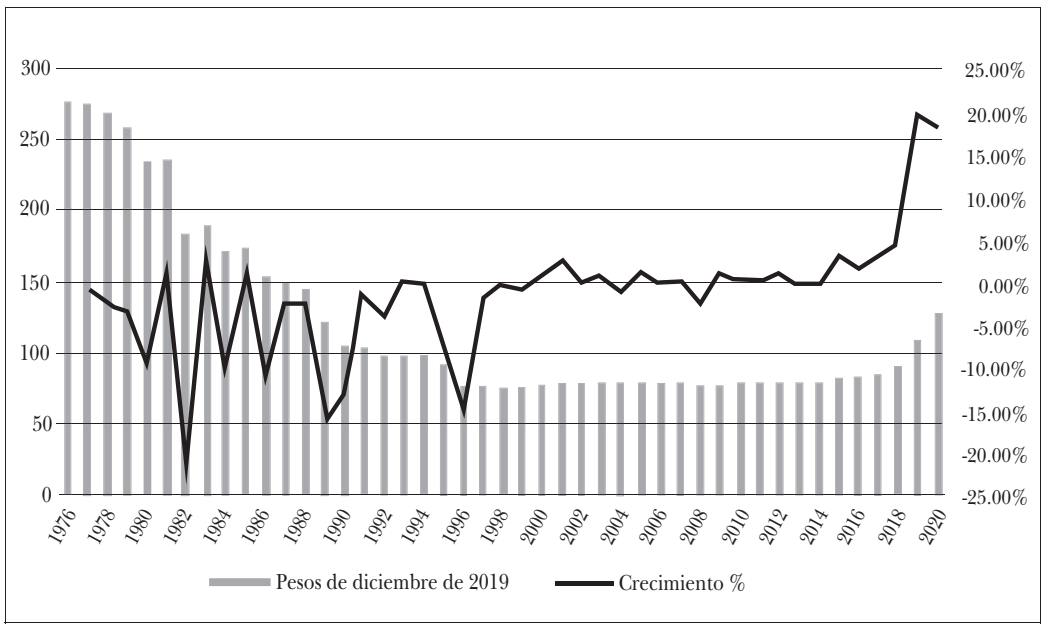

Fuente: Comisión Nacional de Salarios Mínimos, Consami.

Corresponde también al T-MEC la autoría de otra de las políticas más celebradas del gobierno de AMLO: una nueva legislación laboral que fortalece los derechos de los trabajadores

${ }^{48}$ El nuevo acuerdo introdujo el concepto de "valor de contenido laboral" en el capítulo 4, "Reglas de origen". Impulsado por el gobierno de Trump, ese concepto busca generar un aumento de los salarios en la industria automotriz y de autopartes establecida en México -la cual está concentrada en la frontera norte- con la expectativa de estimular la retención de la inversión automotriz dentro de Estados Unidos. 
mexicanos. La nueva Ley introdujo, por ejemplo, el voto libre y secreto para la elección de direcciones sindicales, así como el establecimiento de tribunales laborales. Esta medida, que debilita a los líderes charros, fue impuesta a México a partir de una alianza circunstancial entre el gobierno de Canadá y los sindicatos de Estados Unidos (principalmente, la AFL-CIO) durante las negociaciones del T-MEC. ${ }^{49}$

Luisa María Alcalde, secretaria del Trabajo, abiertamente expresaría que "México se comprometió a temas muy concretos en el apartado laboral y esos compromisos se incorporaron en la reforma laboral". Además, afirmaría en tono de celebración: "Al fin Estados Unidos y Canadá plantean que en México los salarios son tan bajos y condiciones precarias que se apuesta a la mejora salarial, libertad y democracia". ${ }^{50}$

La naturaleza bicéfala de cualquier hegemonía, compuesta por coerción y consentimiento, se expresa en el México contemporáneo en el binomio de una Presidencia poderosa con legitimidad para girar el volante a la izquierda. Sin embargo, la mesura de AMLO hacia el gran capital ha desfigurado sus aspiraciones redistributivas. La decisión de financiar sus programas sociales a partir de la austeridad en diversas áreas del aparato estatal -y sin una reforma tributaria progresiva- revela el alcance (y el fracaso) del "posneoliberalismo" mexicano. En este sentido, no es un dato menor que haya sido el T-MEC el responsable del aumento al salario mínimo y de la reforma laboral en México. En perspectiva latinoamericana, el progresismo mexicano destaca por su debilidad: muy poco, muy tarde.

${ }^{49} \mathrm{Al}$ igual que las nuevas reglas de origen, la intención del capítulo 23 "Laboral" del nuevo acuerdo es causar un aumento salarial en México para evitar la fuga de puestos de trabajo desde Canadá y Estados Unidos. Sobre la alianza de sindicatos de Estados Unidos con el gobierno canadiense en este punto, ver el recuento de las primeras fases de negociación de Arthur Stamoulis, "NAFTA Talks: What's the Deal?", Labor Notes, 31 de octubre de 2017.

${ }^{50}$ Marisol Velázquez, "Con reforma laboral, se cumplieron los compromisos del T-MEC: STPS”, El Economista, 27 de noviembre de 2019. 


\section{LÓGICA DEL PROGRESISMO FALLIDO}

El posneoliberalismo es un impulso político menos homogéneo que su antecesor, el statu quo neoliberal, el cual, pese a las especificidades nacionales, respondía a un patrón común de fortalecimiento internacional del capital. ${ }^{51}$ Aun así, la noción del posneoliberalismo es de utilidad si se le entiende "no como un rompimiento total con el neoliberalismo, sino como una tendencia a romper con ciertos aspectos de las fórmulas de la política neoliberal, sin representar un grupo de políticas estrictas o un régimen de políticas claramente identificable". ${ }^{52}$ A pesar de su falta de nitidez, diversos autores convergen en clasificar los esfuerzos posneoliberales en un arco de mayor a menor ruptura con el modelo precedente, donde Venezuela y Brasil constituyen los dos extremos. En términos de su relación con el capital, el gobierno de Chávez representaría una política de coexistencia, mientras la de Lula encarnaría la de colaboración.

La política de coexistencia supone una tensión Estadocapital donde el primero no rechaza la existencia del segundo, pero sí rechaza (en parte, al menos) las relaciones de propiedad constituidas en la neoliberalización; de ahí las

51 "Since post-neoliberalism lacks a powerful and wealthy sponsor like the United States or the International Monetary Fund, and is more strongly rooted in local politics and culture, it is probably even more variegated than its neoliberal predecessor" (Dado que el posneoliberalismo carece de un patrocinador poderoso y acaudalado como Estados Unidos o el Fondo Monetario Internacional, y es más fuerte su arraigo en la política y cultura locales, es probable que sea aun más abigarrado que su predecesor neoliberal", Arne Ruckert, Laura Macdonald y Kristina R. Proulx, "Post-neoliberalism in Latin America: a conceptual review", Third World Quarterly 38, núm. 7 (2017), p. 1585, https://doi.org/10.1080/014 36597.2016.1259558

${ }^{52}$ Ruckert, Macdonald, y Proulx, p. 1584. Cita original: "not as a complete break with neoliberalism, but rather as a tendency to break with certain aspects of neoliberal policy prescriptions, without representing a set of strict policies or a clearly identifiable policy regime" (traducción de la editora). 
eventuales iniciativas por revertir las privatizaciones del periodo anterior. La segunda política, por otra parte, supone la aceptación por parte del Estado de los avances del capital durante el neoliberalismo, pero sin aceptar la previa pasividad del Estado frente a sus consecuencias sociales. A este tipo de estrategia, pero en una iteración más moderada, pertenece el México de AMLo (y este ha sido, en efecto, el principal argumento de este artículo). Esta situación confirma la tesis de Stolowicz, quien indica que el grueso de los esfuerzos posneoliberales en América Latina ha consistido no en superar la dominación neoliberal, sino en hacerle un ajuste táctico, restaurando (sobre nuevas bases) su legitimidad y, por lo tanto, su hegemonía. ${ }^{53}$

Cuando Peña Nieto privatizó en 2013 los yacimientos petrolíferos futuros, el expresidente Zedillo (1994-2000), tecnócrata neoliberal, admitió que "ni en mis salvajes sueños esperé ver los cambios constitucionales alcanzados". ${ }^{4}$ Algo se perdió en México durante el doble giro democrático y neoliberal; algo de tal calado que incluso el gobierno "de izquierda" y "posneoliberal" de AMLo se siente (y, por ello, está) obligado a honrar la reforma energética. En una reveladora entrevista para Reuters, Carlos Urzúa, poco antes de la elección de 2018, explicaba que la política económica de AMLo estaría “a la derecha de Lula". 55

Lejos de los tiempos en que denunciaba las privatizaciones y el Fobaproa, AMLO aprendió a amar a la burguesía. Si en 2006 su lema era "Por el bien de todos, primero los pobres", en 2018 fue "Por un gobierno para ricos y pobres". No

${ }^{53}$ La identificación de la izquierda latinoamericana con esa estrategia es, para Stolowicz, la prueba de que "una nueva hegemonía burguesa... ha hecho mella incluso entre quienes se consideran críticos". Beatriz Stolowicz, "El 'progresismo posneoliberal' en la estrategia del capital para América Latina”, Argumentos 86 (2018), p. 107.

54 Juan Carlos Pérez Salazar, "México pone fin a más de 70 años de monopolio petrolero", BBC News, 11 de agosto de 2014.

55 Jean Yoon y Paritosh Bansal, "Mexican election favorite is 'really not leftist,' adviser tells investors”, Reuters, 6 de junio de 2018. 
sólo le entregó a un representante de la alta burguesía, Alfonso Romo, el trazado de su "Proyecto de nación" como candidato, sino que luego lo convirtió en su mano derecha, el jefe de Oficina de la Presidencia.

El progresismo fallido es el resultado del colaboracionismo de AMLO, tan pronunciado que lo ha cancelado como ruptura posneoliberal. La paradoja de un giro a la izquierda tan drástico como impotente -esto es, la Presidencia más poderosa registrada en la joven democracia mexicana y su docilidad frente a los intereses del gran capital- no significa para nada que el régimen sea débil. El lopezobradorismo, más bien, acusa una fortaleza selectiva, orientada al reordenamiento de las instituciones federales en función de una centralización del poder en manos de la Presidencia. Lo anterior no es sorprendente si, como he argumentado a lo largo de este artículo, aceptamos que no es la izquierda lo que llegó al poder, sino su remplazo; en todo caso, una izquierda pirata. A diferencia de la izquierda socialista -en sus diversas derivaciones- que ubicaba en la economía política el núcleo de la experimentación redistributiva, estamos frente a un populismo domesticado cuyo radio de acción quedó (auto)reducido al rediseño de la burocracia estatal y sólo a ella.

Prueba de la recentralización es la creación de los "delegados federales" en cada estado de la República -también llamados superdelegados-, quienes son agentes directos de la Presidencia para supervisar la operación subnacional de las instituciones federales. ${ }^{56}$ En una especie de reforma borbónica, AMLo busca recuperar el poder de la Presidencia que se dispersó con la democracia. Su esfuerzo por restaurar el brillo de la silla presidencial tiene sentido cuando se recuerda

56 Laura Arreazola, “AMLO revela nueva estructura para los superdelegados ¿cómo funciona?”, Político, 20 de marzo de 2019. Curiosamente, el antecedente de la figura del superdelegado está en el sexenio de Peña Nieto, con su nombramiento ad hoc del "enviado especial" en Michoacán, Alfredo Castillo, quien fungió como operador directo de la Presidencia, en ocasiones sustituyendo al gobernador, en el contexto de una crisis de violencia. 
que él tiene origen priista y, como tal, desea trascender a través de obras faraónicas al estilo del viejo PRI. De esa lógica proceden sus megaproyectos, como la refinería Dos Bocas, el Tren Maya, el Corredor Transístmico o el Aeropuerto de Santa Lucía, a los que se ha aferrado pese a los devastadores efectos de la pandemia de Covid-19. La austeridad podrá afectar diversas áreas del gobierno, pero no sus megaobras.

La derechización de AMLO ha inspirado críticas de sus antiguos compañeros de armas priistas. Cuauhtémoc Cárdenas, por ejemplo, durante la campaña electoral le cuestionó que no busque revertir la constitucionalización de la reforma energética y, más recientemente, le sugirió "diferir los megaproyectos" a fin de liberar "todos los recursos que sean posibles" para enfrentar la pandemia y sus efectos. ${ }^{57} \mathrm{Si}$ bien la política de AMLO para la pandemia escapa el alcance de este artículo, aquí he advertido que su gobierno no está atado de manos. Por ejemplo, el gobierno de AMLo cuenta con la inédita capacidad (en democracia) de reformar la Constitución con facilidad, casi a placer, en virtud de su predominio en el Congreso de la Unión y en los congresos locales. Por lo tanto, pudo revertir la constitucionalización del neoliberalismo, que incluye lo relativo a la reforma energética (por ejemplo) y cuyo momento fundacional es la reforma al artículo 27 en 1992.

En efecto, AMLo ya ha usado su poder para reformar la Constitución, pero no hacia la izquierda. La presencia del Ejército y la Marina en las calles, llevando a cabo tareas de seguridad interna desde que inició la guerra contra el narco en 2006, era una irregularidad jurídica que AMLo ha normalizado con el Decreto 235, el cual rebasa por la derecha a los gobiernos de Peña Nieto y Calderón. ${ }^{58}$ Ese Decreto, además de

${ }^{57}$ Horacio Jiménez, "Mi voto, para AMLo o quien revierte reforma energética: Cuauhtémoc Cárdenas", El Universal, 29 de mayo de 2018; "Sugiere Cárdenas a AMLO aplazar megaobras ante crisis económica", La Razón, 5 de junio de 2020.

${ }^{58}$ Dicha postura no es un rayo en cielo raso. No hay que olvidar que, en 2006, en reunión privada con el embajador de Estados Unidos 
consumar lo que él y el PAN no lograron, creó una nueva corporación armada, la Guardia Nacional, con mando militar y subordinada a la Sedena, a diferencia de su predecesora, la Policía Federal, que era de mando civil y dependía de una institución civil, la Secretaría de Seguridad Pública.

Las fuerzas armadas mexicanas no sólo han incrementado su peso dentro del régimen, sino que han profundizado el viraje en su doctrina: de fuerza contra una agresión externa a garante del orden interno. Por supuesto, este desarrollo va en un sentido contrario al contexto que explica la irrupción del progresismo de AMLO: es decir, el contexto generado por Ayotzinapa. La desaparición de 43 estudiantes de esta escuela normal rural fue el punto de inflexión en el sexenio de Peña Nieto; el punto que determinó la caída en su popularidad y del que nunca se recuperó. Tan sólo unos meses antes de la crisis de Ayotzinapa, Peña Nieto aparecía como un héroe de talla internacional al que, por ejemplo, la revista Time colocó en portada con la frase: "Salvando a México". La reforma energética, cuya aprobación estaba en curso, fue el clímax de su sexenio. Pero Ayotzinapa abrió una crisis en la que el Ejército quedó comprometido -por su participación, nunca aclarada-, lo cual contribuyó a abrir la ventana de oportunidad para el triunfo electoral del progresismo. Ya en el poder, AmLo liberó al Ejército de cualquier investigación que lo involucrara con los 43.59

Es revelador que, en el contexto de la austeridad "republicana”, el presupuesto del Ejército haya aumentado $25 \%$ en el primer año de AMLO y que lo mantenga en niveles por encima de los sexenios previos. Lo anterior puede observarse en la gráfica 3:

en México, AmLo se plegaba a las demandas de Washington, prometiendo "dar al ejército mayor poder y autoridad al ejército en operaciones antinarcóticos”. Wikileaks, "Apocalypse not: AMLO assures ambassador he will have a strong, sound administration”, México, 2006.

${ }^{59}$ Arturo Rodríguez García, "Nueva comisión para el caso Ayotzinapa no investigará al Ejército: Encinas”, Proceso, el 26 de septiembre de 2018. 


\section{GrÁfica 3}

Gasto de la Secretaría de la Defensa Nacional

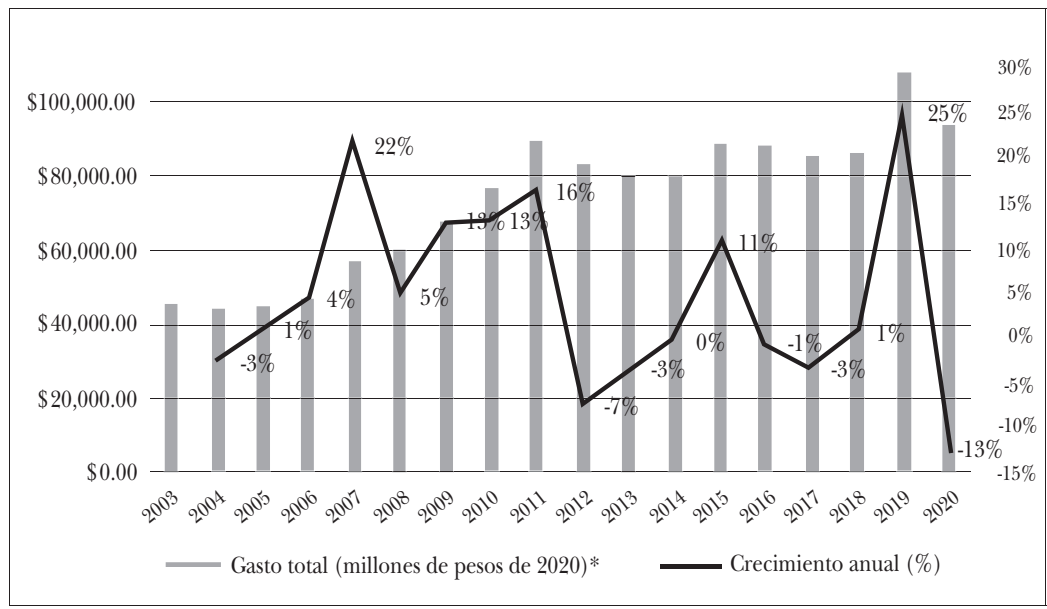

Fuente: elaboración propia a partir datos de la SHCP.

* Nota: para los años 2010-2019, tomé el gasto neto; y, para 2020, el presupuesto original.

Por si fuera poco, el Ejército ha incursionado en el mundo empresarial, a partir de que AMLO le otorgara la concesión para construir, operar y administrar el Aeropuerto de Santa Lucía, uno de sus megaproyectos emblema. ${ }^{60}$ La hipertrofia de las fuerzas armadas dentro del régimen a manos de "la izquierda" en el poder se inscribe en el esfuerzo de AMLO, como decía párrafos atrás, para restaurar la centralidad de la Presidencia. Un proceso, sin embargo, lejos del nacionalismo revolucionario que está en la raíz del populismo del que procede. Aunque en este artículo me he centrado en la nulidad revolucionaria de AMLO, no está de más aludir lo lejos que también está del nacionalismo y el antimperialismo.

${ }^{60}$ Jacobo García, "El Ejército mexicano aumenta su poder con la construcción y explotación del nuevo aeropuerto", El País, 20 de marzo de 2020 . 
Subordinado desde la primera hora a Estados Unidos, no ofreció resistencia a la amenaza de Donald Trump de imponer aranceles a las exportaciones mexicanas a menos que México detuviera el flujo de migrantes centroamericanos. Fácilmente, Trump logró convertir a la frontera entre México y Guatemala en la nueva frontera sur de Estados Unidos. Más allá del lenguaje metafórico de la anterior afirmación, 2400 efectivos, elementos de la Guardia Nacional, fueron inmediatamente asignados a la frontera de Chiapas con Guatemala para realizar, en franco modo de outsourcing, tareas de la Border Patrol. ${ }^{61}$ En su visita a Washington, D.C., AMLo diría a Trump: "Gracias por no tratarnos como colonia". ${ }^{62}$

En el mismo plano internacional, es significativa la continuidad de AMLo con la Alianza del Pacífico, impulsada por los anteriores gobiernos mexicanos para coaligarse con los Estados neoliberales de la región que escaparon al giro a la izquierda: Colombia, Perú y Chile. En contraste con otros regionalismos, expresados en iniciativas como el ALBA -impulsado por Venezuela- o el Unasur -auspiciado por Brasil-, la agenda exterior del progresismo mexicano consiste en convencer a Estados Unidos de que impulse en la región una "Alianza para el Progreso", con México como socio menor. Por otro lado, y más allá de la vocación latinoamericanista, también es revelador el respaldo de AMLO al TLCAN y su sucesor, el T-MEC. En contraste no sólo con su pasado -él fue opositor al TLCAN en la década de los noventa-, el progresismo mexicano se separa en este punto, radicalmente, del giro a la izquierda sudamericano, que tuvo como uno de sus actos inaugurales el rechazo coordinado -de Chávez, Kirchner y Lula- al Área de Libre Comercio para las Américas en 2005,

${ }^{61}$ Alberto Pradilla, "En frontera sur, 2,400 elementos de la Guardia; no detendrán a migrantes, asegura el gobierno”, Animal Político, 17 de junio de 2019.

62 “'Usted no ha pretendido tratarnos como colonia': El discurso completo de Amlo junto a Trump en la Casa Blanca”, Animal Político, 8 de julio de 2020, https:/ /www.animalpolitico.com/2020/07/amlo-discurso-comple to-casa-blanca/ 
impulsado por George W. Bush como una expansión del TLCAN a nivel hemisférico.

En vez de encarnar el renacimiento del progresismo en América Latina, el gobierno de AMLO es la confirmación de su agotamiento. En esa constelación, el caso mexicano representa el populismo menos disruptivo y más domesticado, el más neoliberal.

\section{HorizonTE}

Citando al general Francisco J. Múgica, precursor del cardenismo, López Obrador ha insistido en que el progreso de México sería el producto "de la simple moralidad y de algunas pequeñas reformas”. Sólo que AMLo predica más moralidad que reformas, y estas últimas no han sido pequeñas, sino pequeñísimas. No se puede afirmar que México tenga un gobierno de izquierda. Esa es una ilusión política que, de mantenerse, conlleva el efecto adverso de retrasar el resurgimiento de la izquierda en este país. En este artículo he diagnosticado que López Obrador encabeza un progresismo fallido que lo coloca en el centro, aunque reclinándose hacia la derecha, del espectro político. El neoliberalismo está intacto.

Por un lado, el régimen mexicano se desplazó hacia la derecha durante la democratización y la neoliberalización. Por el otro, la oposición al statu quo perdió su izquierda socialista y su espacio fue ocupado por el tipo de populismo que había sido el centro. Esta situación facilitó que la victoria de esa izquierda pirata fuera sobreestimada en 2018; el país se había desplazado tanto a la derecha que una opción ligeramente crítica parecía una ruptura. De ahí la paradoja de un "giro a la izquierda" tan drástico como impotente; el mayor poder presidencial registrado en democracia se mostró incapaz de afectar al capital. En este sentido, el "posneoliberalismo" de AMLO es meramente retórico, porque no hay ruptura alguna no sólo con las relaciones de la propiedad sino con la política social previa; en cambio, AMLo sí ha cen- 
tralizado el poder en la Presidencia en favor de sus megaproyectos y el Ejército.

El análisis que he aportado en este artículo sobre el ascenso del progresismo al poder tiene implicaciones para discernir el horizonte de la izquierda en México. En la era neoliberal, el proyecto político que AMLo encabeza desde 2006 ha logrado domesticar al "tigre" de la revolución, y en esa virtud descansa su cortejo al gran capital: somos nosotros o el caos. ${ }^{63}$ En este sentido, algo ha cambiado en Morena en su tránsito desde la oposición hacia el poder.

El colaboracionismo de López Obrador no fue ningún obstáculo para su ascenso al poder. Al contrario, en esa naturaleza descansa su éxito: en su apelación al voto como vía para la transformación política sin necesidad de radicalismo alguno. En este sentido, Morena y, antes, el PRD, desviaron enfrentamientos con el gran capital en función del voto en su favor. Así, el voto por Morena ha sido desde la atomización; desde la expectativa de cambio sin acción colectiva o donde ésta tiene como única expresión el voto por Morena. Pero Morena ya llegó al poder. Y si bien el de AMLo es un gobierno que atrajo una amplia popularidad -treinta millones de votantes que optaron por darle una oportunidad a "la izquierda"-, su capacidad para contener futuros brotes de polarización está en entredicho.

Por su relación con el capital desde el poder, han quedado comprometidas las credenciales del progresismo mexicano como oposición al neoliberalismo. Por otra parte, esta expresión política ha ganado espacio como partido dominante del sistema político mexicano. El significativo debilitamiento de la tríada de partidos que dominaron la política nacional desde los noventa (PRI, PAN y PRD) y el concomitante ascenso de Morena, colocan a México en la antesala de una nueva ecuación política. Una donde, por un lado, Morena es el principal guardián del neoliberalismo y donde la oposición

${ }^{63}$ Misael Zavala, "AMLO: si hay fraude, yo no amarraré 'al tigre”, $E l$ Universal, 10 de marzo de 2018. 
a éste vive una "crisis de dirección" (en virtud del desplazamiento de AMLO como líder de la oposición a guardián del statu quo).

¿Era más funcional al status quo la situación de AMLO como eterno opositor? ¿Su ascenso al poder desbloqueará la radicalización en las filas opositoras al capital? ¿Cómo responderá el gobierno de AMLO en el resto del sexenio para mantener un perfil "progresista”, "posneoliberal”? ¿Será suficiente tal respuesta? La respuesta a estas preguntas, por supuesto, escapan al alcance de este artículo y son materia de discusión futura, incluyendo, desde luego, al propio gobierno obradorista y a quienes pretendan sucederlo.

\section{Bibliografía}

Agren, David, "AMLO's Mexico leads to drastic cuts to health system”, The Lancet 393, núm. 10188, 8 de junio de 2019, pp. 2289-2290, https://doi.org/10.1016/S0140-6736(19)31331-5

Alanís, Ma. del Carmen, "Carpizo y la reforma de 1994: una perspectiva neoinstitucional individualista”, en Miguel Carbonell, Héctor Fix y Diego Valadés (eds.), Estado constitucional, derechos humanos, justicia y vida universitaria. Estudios en homenaje a Jorge Carpizo, 1, pp. 33-52. México, unam, 2015.

Álvarez, Ernestina, "PAN pide a OEA llamar al gobierno a la estabilidad democrática en México", mvs Noticias, 29 de marzo de 2019.

"AMLO dice que el $90 \%$ de las llamadas sobre violencia contra las mujeres son falsas", Animal Político, 15 de mayo de 2020.

“AmLo en Los Reyes Acaquilpan”, México, American News, 2018. Anderson, Perry, The H-Word. The Peripeteia of Hegemony, Londres, Verso, 2017.

Arreazola, Laura, "AMLo revela nueva estructura para los superdelegados ¿cómo funciona?”, Político, 20 de marzo de 2019.

Bizberg, Ilán, "México: una transición fallida", Desacatos, núm. 48, 2015, pp. 122-139. 
Bolívar Meza, Rosendo, "Movimiento de Regeneración Nacional: democracia interna y tendencias oligárquicas", Foro Internacional 57, núm. 2, pp. 460-489, https://doi.org/10.24201/fi.v57i2.2385 Castañeda, Jorge G., "Latin America's Left Turn", Foreign Affairs 85, núm. 3, 2006, pp. 28-43, https://doi.org/10.2307/20031965 Centeno, Ramón I., "Zapata reactivado: una visión žižekiana del Centenario de la Constitución”, Mexican Studies/Estudios Mexicanos 34, núm. 1. 2018, pp. 36-62, https://doi.org/10.1525/ msem.2018.34.1.36

Comisión Nacional de Salarios Mínimos, Conasami, "Boletín No. 002/2019", México, 2019.

"Entrevista en casa de AMLo", México, tv Azteca, 2018.

EsPejEL, Alberto, "Orígenes organizativos y derroteros estatutarios del Movimiento de Regeneración Nacional y el Partido de la Revolución Democrática. Entre carisma y grupos políticos", Estudios Políticos 35, 2015, pp. 103-128, https://doi.org/10.1016/ J.ESPOL.2015.03.002

Espinoza Toledo, Ricardo y Juan Pablo Navarrete Vela, "moreNA en la reconfiguración del sistema de partidos en México", Estudios Políticos37, 2016, pp. 81-109, https://doi.org/10.1016/ J.ESPOL.2016.02.004

Estévez, Dolia, "Con AMLo ganó la izquierda del PRI, y no la izquierda histórica, dice el historiador John Womack", Sin embargo, 28 de julio de 2018.

García, Jacobo, "El Ejército mexicano aumenta su poder con la construcción y explotación del nuevo aeropuerto", El País, 20 de marzo de 2020.

Harvey, David, A Brief History of Neoliberalism, Oxford, University Press, 2005.

Hernández Rodríguez, Rogelio, "El refugio del PRI durante la alternancia panista”, Foro Internacional 55, núm. 1, 2015, pp. 45-82.

Jaramillo, Máximo, “¿Una nueva política social?: cambios y continuidades en los programas sociales de la 4T”, Análisis Plural, julio-diciembre de 2019, pp. 137-154.

Jiménez, Horacio, "Mi voto, para AMLO o quién revierte reforma energética: Cuauhtémoc Cárdenas”, El Universal, 29 de mayo de 2018. 
Katz, Claudio, "Desenlace del ciclo progresista", Estudios críticos del desarrollo 7, 2017, pp. 87-122.

LANZARO, Jorge, "La 'tercera ola' de las izquierdas latinoamericanas: entre el populismo y la social-democracia”, Encuentros Latinoamericanos 1, núm. 1, 2008, pp. 20-57.

Lanzaro, Jorge, Social Democracias "Tardias" Europa Meridional y América Latina, Madrid, Centro de Estudios Políticos y Constitucionales, 2014.

Linz, Juan J., "The perils of presidentialism”, Journal of Democracy 1, núm. 1, 1990,pp.51-69, https://doi.org/10.1353/jod.1990.0011

López Obrador, Andrés Manuel, 2018 La Salida, México, Planeta, 2017.

López Obrador, Andrés Manuel, "Discurso del presidente Andrés Manuel López Obrador en su informe al pueblo de México", Presidencia de la República, 5 de abril de 2020.

Luxemburg, Rosa, Reforma o revolución, https://www.marxists.org/ espanol/luxem/1900/reform-revol.htm

Meyer, Lorenzo, "Felipe Calderón o el infortunio de una transición”, Foro Internacional 55, núm. 1, 2015, pp. 16-44.

"Huelga en Matamoros no beneficia a nadie: stPs", Forbes, 25 de enero de 2019.

"Preocupa política de gasto; austeridad afectó PIB: HR Ratings", $E l$ Economista, 11 de agosto de 2019.

O'Donnell, Guillermo, "Poverty and Inequality in Latin America: Some Political Reflections", The Kellogg Institute Working Papers, núm. 225, 1996, pp. 1-26.

"Para López Obrador, legalizar el aborto y el matrimonio gay no es algo 'tan importante'", Animal Político, 12 de junio de 2015.

Pérez Salazar, Juan Carlos, "México pone fin a más de 70 años de monopolio petrolero", BBC News, 11 de agosto de 2014.

Pradilla, Alberto, "En frontera sur, 2,400 elementos de la Guardia; no detendrán a migrantes, asegura el gobierno", Animal Político, 17 de junio de 2019.

Presidencia de la República, "Decálogo para salir del coronavirus y enfrentar la nueva realidad", México, 2020.

Presidencia de la República, "La nueva política económica en los tiempos del coronavirus”, México, 2020. 
Presidencia de la República, Plan Nacional de Desarrollo 2019-2024, México, 2019.

Przeworski, Adam, "How Many Ways Can Be Third?", en Social Democracy in Neoliberal Times. The Left and Economic Policy since 1980, pp. 312-333, Oxford, University Press, 2001.

Ríos, Viri, "En México solo hay dos partidos: conservador y conservador", The New York Times, 16 de junio de 2020.

Rodríguez Araujo, Octavio, "México, proceso y afianzamiento de un nuevo régimen político", Andamios 6, núm. 11, 2009, pp. 205-234.

Rodríguez García, Arturo, "Nueva comisión para el caso Ayotzinapa no investigará al Ejército: Encinas”, Proceso, 26 de septiembre de 2018.

Ruckert, Arne, Laura Macdonald y Kristina R. Proulx, "Postneoliberalism in Latin America: a conceptual review", Third World Quarterly 38, núm. 7, 2017, pp. 1583-1602, https://doi.or $\mathrm{g} / 10.1080 / 01436597.2016 .1259558$

SAder, Emir y Pablo Gentili (eds.), La trama del neoliberalismo ( $2^{\mathrm{a}}$ ed.), Buenos Aires, clacso, 2003.

Secretaría de Hacienda y Crédito Público, shcP, "Criterios Generales de Política Económica para la Iniciativa de Ley de Ingresos y el Proyecto de Presupuesto de Egresos de la Federación Correspondientes al Ejercicio Fiscal 2019”, México, 2018.

Secretaría de Hacienda y Crédito Público, sHCP, "Informe sobre la situación económica, las finanzas públicas y la deuda pública. Segundo trimestre 2019”, México, 2019.

Stamoulis, Arthur, "NAFTA Talks: What's the Deal?", Labor Notes, 31 de octubre de 2017.

Stolowicz, Beatriz, "El 'progresismo posneoliberal' en la estrategia del capital para América Latina”, Argumentos 86, 2018, pp. 105-127.

"Sugiere Cárdenas a AMLO aplazar megaobras ante crisis económica”, La Razón, 5 de junio de 2020.

Traverso, Enzo, Melancolía de izquierda, Barcelona, Galaxia Gutenberg, 2019.

Urrutia, Alonso y Dora Villanueva, "López Obrador decreta el ‘fin de la época neoliberal", La Jornada, 18 de marzo de 2019. 
“'Usted no ha pretendido tratarnos como colonia': El discurso completo de AmLo junto a Trump en la Casa Blanca", Animal Político, 8 de julio de 2020, https://www.animalpolitico.com/ 2020/07/amlo-discurso-completo-casa-blanca/

VELÁzQuez, Marisol, "Con reforma laboral, se cumplieron los compromisos del T-MEC: stps”, El Economista, 27 de noviembre de 2019.

Weyland, Kurt, "Neoliberalism and democracy in Latin America: A mixed record", Latin American Politics and Society 46, núm. 1, 2004, pp. 135-157.

Wikileaks, "Apocalypse not: AMLO assures ambassador he will have a strong, sound administration", México, 2006.

Yoon, Jean y Paritosh Bansal, "Mexican election favorite is 'really not leftist,' adviser tells investors", Reuters, 6 de junio de 2018.

Zavala, Misael, “AMLO: si hay fraude, yo no amarraré 'al tigre'”, $E l$ Universal, 10 de marzo de 2018. 
